\title{
Você é lingüista ou pregador? Elaboração de uma tipologia estilística dos poetas brasileiros contemporâneos
}

Antonio Vicente PIETROFORTE (FFLCH-USP)

RESUMO: Com base no modelo proposto por J. M. Floch em seu estudo a respeito do comportamento dos usuários do metrô de Paris, apresentamos um modelo para o estudo dos diversos estilos da poesia brasileira contemporânea.

PALAVRAS CHAVE: semiótica; estilo; poesia; literatura brasileira.

ABSTRACT: Based on the model proposed by J. M. Floch in his study about Paris subway users behavior, we present a model for the study of differents styles of the contemporany brazilian poetry.

KEYWORDS: semiotics; style; poetry; brazilian literature. 
A diversidade das formas de expressão da poesia brasileira contemporânea é uma das características mais evidentes para quem se dedica à sua leitura. Dos sonetos de Glauco Mattoso às experiências visuais de Arnaldo Antunes e Ricardo Aleixo, há haikais de Alice Ruiz e Paulo Leminsky, fluxos contínuos de Roberto Piva, versos livres de Jorge Mautner e Cuti, versos trabalhados, mas de modos diferentes, de Joca Terron, Afonso Ávila, Geraldo Carneiro, Cláudio Daniel, Hilda Hilst, etc. Essa variedade formal, além do mais, não pode ser relacionada a poetas de modo simples e linear: não há para cada poeta uma forma, mas formas poéticas trabalhadas diferentemente por poetas distintos. Glauco Mattoso, por exemplo, embora faça sonetos em seus trabalhos mais recentes, fez poesia visual no Jornal Dobrabil; e em Ademir Assunção podem ser encontrados versos metrificados, versos livres e poemas visuais.

Tamanha riqueza poderia levantar a suspeita de que a literatura contemporânea no Brasil, senão caótica, é, pelo menos, difusa. Caótica, no sentido de desorganizada, ela não é. Um poeta e sua poesia não pairam sobre as transformações da literatura alienado das formas poéticas colocadas historicamente a seu dispor. $\mathrm{Na}$ tensão discursiva em que poeta e literatura fazem sentido - em que poetas definem formas na medida em que são definidos por elas - é possível verificar as encruzilhadas nas quais uma forma de expressão é correlacionada a uma forma de conteúdo, funcionando tanto para fixar quando para desestabilizar o fazer literário.

Durante o período da literatura ocidental chamado Classicismo, a forma de expressão própria do soneto está correlacionada a conteúdos cujos temas são considerados nobres; e a forma de expressão própria das redondilhas, a temas considerados vulgares. Para as damas da corte, os poetas fazem sonetos; para as lavadeiras, redondilhas. No entanto, embora fixada nessa época, tal correlação é desestabilizada quando a poesia posterior reutiliza a forma de expressão do soneto com conteúdos escatológicos, como fazem Bocage e Glauco Mattoso.

Desse modo, embora difusa, a poesia contemporânea brasileira pode ser sistematizada com base na prática literária da re-invenção formal, entendendo forma poética na correlação entre uma forma de expressão e uma forma de conteúdo.

\section{A semiótica e os regimes de interação}

Sistematizar a prática dos poetas brasileiros contemporâneos com base na utilização de formas poéticas é, antes de tudo, determinar estilos organizados em torno de modos de coesão específicos.

O modo de coesão pode ser definido como as coerções, tanto na forma da expressão quanto na forma do conteúdo, que um gênero discursivo estabelece para se fixar. O soneto clássico, por exemplo, define um modo de coesão, assim como o romance romântico. 
Em torno desses estilos ou modos de coesão, são construídos regimes de interação, ou seja, para cada modo de coesão poética há um regime de interação do poeta, que se define em relação ao regime escolhido e aos demais regimes preteridos, do mesmo modo que define sua poesia.

Ao estudar as interações entre sujeitos, a semiótica define os chamados modos de identidade. Sobre o tema, um dos trabalhos mais significativos é o texto "Êtes-vous arpenteur ou somnambule? L'elaboration d'une typologie comportementale des voyager du mêtro" (Floch, 1995: 19-47), de Jean-Marie Floch.

Floch, analisando o percurso dos passageiros do metrô de Paris, verifica que seus comportamentos podem ser sistematizados pelo modo como executam as trajetórias. Um passageiro pode, então, afirmar a continuidade ou a descontinuidade de seu percurso. Aquele que lê, tricota, escuta o discman, etc, afirma a continuidade, ou seja, passa indiscriminadamente pelas estações; já aquele que discrimina cada uma delas e sabe suas peculiaridade, afirma a descontinuidade. São os percursos, respectivamente, do sonâmbulo e do geômetra.

Articulando a categoria formal continuidade vs. descontinuidade em um quadrado semiótico, geram-se mais duas possibilidades: a negação da continuidade e a negação da descontinuidade. Nega a descontinuidade aquele passageiro que antecipa suas paradas, sempre com bilhete na mão antes de chegar na roleta e levantando-se antes das estações. Por sua vez, nega a continuidade aquele sempre disposto a se distrair com as surpresas do caminho. Ao primeiro, Floch chama executivo, e ao segundo, flanador.

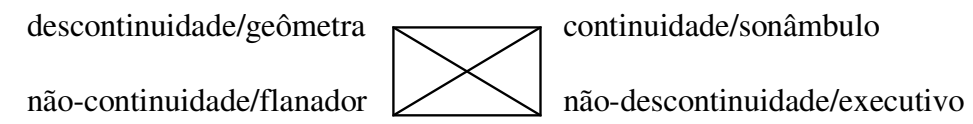

No quadrado são sistematizados, portanto, quatro regimes de interação, definidos de acordo com a relação entre o passageiro e seu estilo de viajar entre as estações.

Se ao invés de usuários do metrô considerarmos poetas e poéticas, podem-se estabelecer relações não mais entre passageiros e trajetórias, mas entre poetas e regimes de interação baseados em estilos literários. Para tal, devem-se determinar os modos de coesão capazes de definir um regime literário e como um poeta pode ser definido em relação a cada regime. 


\section{Por uma tipologia estilística dos poetas brasileiros contemporâneos}

O poeta contemporâneo, assim como o passageiro do metrô, pode construir sua poesia de acordo com a categoria formal continuidade vs. descontinuidade, no caso, aplicada ao modo como trabalha a palavra e o discurso. Para mostrar esses fazeres poéticos, são escolhidos dois poemas e dois poetas: Arnaldo Antunes e Roberto Piva.

Isto

(Arnaldo Antunes)

CR

isto

MEF

Os anjos de Sodoma

(Roberto Piva)

Eu vi os anjos de Sodoma escalando

um monte até o céu

E suas asas destruídas pelo fogo

abanavam o ar da tarde

Eu vi os anjos de Sodoma semeando

prodígios para a criação não

perder seu ritmo de harpas

Eu vi os anjos de Sodoma lambendo

as feridas dos que morreram sem

alarde, dos suplicantes, dos suicidas

e dos jovens mortos

Eu vi os anjos de Sodoma crescendo

com o fogo e de suas bocas saltavam

medusas cegas

Eu vi os anjos de Sodoma desgrenhados e

violentos aniquilando os mercadores, roubando o sono das virgens,

criando palavras turbulentas

Eu vi os anjos de Sodoma inventando

a loucura e o arrependimento de Deus

Enquanto exemplos de concisão e prolixidade, Arnaldo Antunes e Roberto

Piva são representativos de dois regimes poéticos contrários: um em que se afirma a 
descontinuidade da palavra, decompondo-a em seus segmentos constitutivos - como Arnaldo Antunes faz com o pronome demonstrativo "isto" na formação das palavras CRisto e MEFisto; e outro em que se afirma a continuidade da palavra no fluxo discursivo - como faz Roberto Piva no fluxo prosódico, com versos livres e figurativização difusa, em que construiu seu poema.

Ao poeta que escolhe afirmar a descontinuidade, decompondo a palavra e segmentando o discurso de acordo com a fonologia, a morfologia, o léxico e a sintaxe de determinado sistema verbal, propomos chamar poeta lingüista; já ao poeta que escolhe o procedimento contrário, afirmando a continuidade da palavra e do discurso, com versos livres e figurativização difusa, propomos chamar poeta pregador.

O poeta lingüista insiste, na coesão de seu fazer poético, em um processo semiótico ao qual Saussure chama anagramático. Trata-se de um processo semiótico, pois está baseado em correlações entre expressão e conteúdo por meio de signos estabilizados. No poema Isto, a correlação entre expressão fonológica e conteúdo semântico que dão forma ao pronome demonstrativo é estabilizada e ressoa nas palavras Cristo e Mefisto.

Uma paronomásia, em que a proximidade entre significantes aproxima significados, mas não apenas isso. $\mathrm{O}$ anagrama pode ser formado por outras relações entre signos, como, por exemplo, em quiasmos fonológicos. No verso de Delmo Montenegro "tudo sangra sob os estrobos", a sequiência de fonemas "sob" é invertida no final da palavra "estrobos".

Essa correlação entre expressão e conteúdo pode resultar em fazeres poéticos tão engenhosos, que a mesma narrativa formada no conteúdo, semanticamente, encontra paralelos na distribuição fonológica disposta em seqüência nos versos, por meio das palavras. No poema Volátil, de Virna Teixeira, há esse tipo de engenhosidade:

\author{
Volátil \\ (Virna Teixeira) \\ percorria o cenário: \\ olho veloz \\ turbilhão de movimentos \\ atentos \\ abria um buquê \\ de deli- \\ cadezas \\ descria uma curva no ar \\ uma curva na curva \\ do lugar onde
}


[ se esconde.

Na seqüência "abria um buquê de delicadezas", o fazer narrado no plano do conteúdo é colocado em paralelo com as transformações fonológicas de vogais e consoantes. Em "buquê", as vogais /u/ e /ê/ são vogais fechadas, fechadas como o buquê que se abre; no entanto, em "delicadezas", ocorrem as vogais fechadas /i/ e o /ê/, mas também a vogal /a/ - a abertura máxima em língua portuguesa - tão aberta quanto o buquê, agora aberto em "delicadezas".

Quanto às consoantes, os fonemas /b/ e /k/ de "buquê" são consoantes oclusivas, também presentes nos fonemas /d/ e /k/ de "delicadezas". Contudo, na última palavra soam os fonemas /s/ e /z/, consoantes constritivas, que garantem mais fluxo de ar quando se realizam. Assim como as vogais, que se abrem, as consoantes ressoam em paralelo com o fazer semantizado no conteúdo.

O poeta pregador utiliza outro recurso discursivo. Longe de decompor a palavra, ele insiste, de preferência, na fixação de uma frase, mas pode ainda fixar-se em palavras ou traços fonológicos formadores de aliterações ou assonâncias. No exemplo do poema de Roberto Piva, a frase "eu vi os anjos de Sodoma" funciona como tema, a partir do qual as estrofes são complementos e variações.

A fixação não é apenas temática. No caso de Piva, há uma elabora sofisticada, em termos entoativos, que permite a fruição do texto, longe das paradas obrigatórias, próprias de poetas como E. E. Cummings ou Augusto de Campos.

Um exemplo de fixação em aliterações como modo de coesão do texto é o poema Gamo o gamar, de Jorge Mautner. No trecho citado em seguida, basicamente, além da afirmação de valores de liberdade no plano de conteúdo, no plano de expressão o poeta utiliza, como coesão fonológica, a vogal /a/ - oral, nasal ou nasalizada - seguida de consoantes oclusivas nos primeiros versos, e seguida de consoantes constritivas, nos últimos.

Gamo o gamar

(Jorge Mautner)

Amo o amar

Só adianta

Quem canta

E se espanta e espanta

A besteira que é tanta

Vamos aprender a amar

$\mathrm{O}$ nosso ar e lar e mar e dar

e amar e estar

Jamais aprisionar e subjugar- 
controlar-manipular

Mas sim, aliás, se emocionar com o Brás

Com a onça e toda nossa bossa

e tudo que se possa

Na nossa joça ser algo que adoça

e que coça

E remoça pois é nossa como a carroça

e a palhoça

E a roça e a onça de novo com toda

(...)

geringonça

Há ainda mais dois regimes por tratar: aquele em que o poeta nega a descontinuidade, e aquele em que nega a continuidade.

Negar a descontinuidade implica aproximar a palavra do discurso, sem insistir em seus componentes morfo-fonológicos, mas sem o efeito de desbragamento do regime do poeta pregador. Esse efeito intermediário, entre o lingüista e o pregador, aproxima a poesia da fala cotidiana, cria-se o efeito da poesia dita prosaica.

Em termos morfo-fonológicos, negar a descontinuidade é não segmentar a palavra, não insistir em jogos anagramáticos, não fixar padrões métricos de sílabas poéticas; em termos semânticos, evita-se o desbragamento dos pregadores com menos densidade metafórica, o que resulta em menos delírio figurativo. São poemas próximos da prosa, como acontece no regime do pregador, mas são antes conversas que sermões apoteóticos.

Por ser construído em formas prosaicas, propomos chamar a esse estilo o regime do poeta conversador. O poema "Torpedo", de Cuti, é um bom exemplo das características mencionadas acima. Construído na negação da descontinuidade, seus versos são livres, mas há coerência figurativa, já que as considerações do poeta negro em torno de questões raciais estão longe dos delírios de Roberto Piva ou Jorge Mautner:

\section{Torpedo}

(Cuti)

irmão, quantos minutos por dia

a tua identidade negra toma sol

nesta prisão de segurança máxima?

e o racismo em lata

quantas vezes por dia é servido a ela

como hóstia? 
irmão, tua identidade negra tem direito

na solitária

a alguma assistência médica?

ouvi rumores de que ela teve febre alta

na última semana

e espasmos

- uma quase overdose de brancura -

e fiquei preocupado.

irmão, diz à tua identidade negra

que eu lhe mando um celular

para comunicar seus gemidos

e seguem também

os melhores votos de pleno restabelecimento

e de muita paciência

para suportar tão prolongada pena

de reclusão.

(...)

Negar a continuidade, por sua vez, implica estabelecer alguns princípios de regularidade para organizar o fluxo da continuidade do discurso, mas sem desmontar, ainda, morfo-fonologicamente a palavra e a frase. O recurso mais evidente desse regime intermediário entre o pregador e o lingüísta é a fixação de métricas silábicas. Com métrica, nega-se a continuidade dos versos desbragados do pregador, e sem a decomposição das palavras em seus constituintes morfo-fonológicos, não se afirma a descontinuidade verbal.

Além do mais, nesse regime, o poeta coloca-se em posição contrária à do poeta conversador, já que a métrica afasta o poema da prosa. Propomos chamar a esse regime, inspirados na metáfora de João Cabral de Melo Neto entre o arquiteto e o poeta, o regime do poeta arquiteto.

Um soneto de Glauco Mattoso, formado por decassílabos heróicos, é um bom exemplo dessa negação da continuidade:

\section{Flatulento}

(Glauco Mattoso)

O peido, mais que o arroto, inspira o riso

gostoso, desbragado, gargalhado,

da parte de quem pode ter peidado,

enquanto os outros fazem mau juízo. 
Com base no meu caso é que analiso, pois, mesmo estando a sós, enclausurado, gargalho após os gases ter soltado e aspiro meu fedor, feito um Narciso.

Me ponho a imaginar a reação de alguém afeito a normas de etiqueta colhido de surpresa ante o rojão...

Meu sonho era peidar fumaça preta na mesa dum banquete, para então deixar que a gargalhada me acometa...

Ao lado da métrica, a regularidade das rimas é outro recurso poético responsável pela negação da continuidade afirmada pelo poeta pregador, na medida em que todo elemento repetido sistematicamente no plano de expressão, ainda mais no final de cada verso, insiste em afastar a poesia da prosa e em negar a continuidade da palavra falada.

Nos soneto de Glauco, as rimas baseadas nas vogais /a/ e /i/, além de estabelecer a coerência fonológica do poema, simulam a gargalhada narrada no conteúdo; as aliterações em consoantes oclusivas entoam o rumor do "peido"; e as aliterações em consoantes constritivas, o espalhar da "fumaça". Entre o pregador e o lingüista, a insinuação de relações anagramáticas faz parte do regime do arquiteto.

Esquematicamente, os regimes poéticos propostos podem ser sistematizados no seguinte quadrado semiótico:

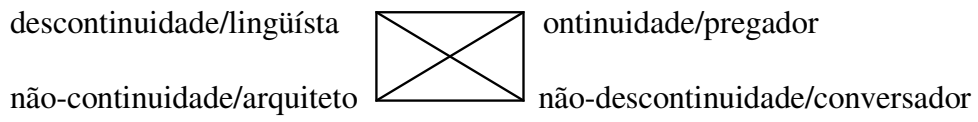

\section{Os regimes poéticos e seus modos de coesão}

Cada regime é definido por uma forma de expressão: o lingüista afirma a descontinuidade desmontando o sistema verbal; o conversador nega a descontinuidade ao respeitar o comportamento lexical sem desmontá-lo; o pregador afirma a continuidade em suas frases livres e desbragadas; e o arquiteto nega a continuidade do discurso ao impor um sistema de escansão para organizar o fluxo entoativo. 
Do lingüista ao pregador, passando pelo conversador, há uma deriva da poesia para a prosa; e do pregador ao lingüista, passando pelo arquiteto, há uma deriva da poesia falada para a poesia visual.

O percurso orientado na afirmação da continuidade está dirigido para a prosa poética, mais afeita à continuidade da palavra e do discurso; já o percurso contrário, orientado na afirmação da descontinuidade, necessita de recursos visuais para marcar a segmentação imposta pela versificação ou pela desmontagem do léxico.

Essas orientações, próprias do plano de expressão da poesia, estão correlacionadas a formas de conteúdo.

O poeta lingüista, ao insistir na desmontagem do sistema verbal, tende a trabalhar sobre conteúdos metalingüísticos, utilizando a linguagem para falar da própria linguagem, como faz Arnaldo Antunes. O poeta arquiteto também faz esse trabalho, mas antes de inventar novas formas, reutiliza e inova formas já consagradas, como Glauco Mattoso faz com o soneto e a literatura de cordel, e Alice Ruiz, com o haikai.

Já o poeta pregador, os insistir no fluxo discursivo, deriva para conteúdos delirantes, como fazem Roberto Piva e Jorge Mautner. Não é por acaso que tais poetas, muitas vezes, são chamados profetas, mesmo que profetas vigaristas, como Jorge Mautner insiste na construção de seu ethos.

O poeta conversador, com versos livres, mas com coerência figurativa menos delirante, geralmente trata de temas engajados, como a maioria dos poetas de esquerda - por exemplo Ferreira Gular - e boa parte dos poetas da chamada literatura negra - por exemplo Cuti. O negação da desconstrução da palavra encaminha o discurso da metalinguagem para a referencialização, de modo que o regime do poeta conversador é útil em engajamentos mais temáticos que metalingüísticos. Cuti, engajado com a literatura negra, escreve no regime do conversador, mas Ricardo Aleixo, que procura desvincular-se desse engajamento, faz poesia visual ou metrificada, atuando nos regimes do poeta lingüista ou arquiteto.

\section{Conclusão}

Os regimes propostos, evidentemente, são regimes democráticos, funcionando antes para a criação que para aprisionamentos formais.

Há poetas, como Joca Terron e Rodrigo Garcia Lopes, que transitam livremente pelos regimes determinados, há poetas mais fiéis a seus próprios regimes, como Glauco Mattoso, Alice Ruiz e Cuti.

Embora determinem derivas de atuação poética, temporariamente fixadas, nada impede que novas correlações sejam estabelecidas. Augusto de Campos, no poema Greve, utiliza no plano de expressão do texto recursos próprios do poeta lingüista, seu 
conteúdo, no entanto, é politicamente engajado; e Carlos Marighela faz sua poesia de esquerda também por meio de formas consagradas, como os poetas arquitetos.

No entanto, como se trata de formalizar antes uma deriva, uma forma de condução discursiva, que um sistema canônico de normas poéticas, o modelo permite inferir o quanto o regime do lingüista carrega de metalinguagem o engajamento político de Augusto de Campos, no poema Greve; ou como o engajamento político de Marighela encontra ornamentação estética quando verbalizado em sonetos ou redondilhas, reforçando o ethos de homem das letras cultas e das armas de fogo, próprio do líder da ALN.

\section{REFERÊNCIAS BIBLIOGRÁFICAS}

ANTUNES, A. (1997) 2 ou + corpos no mesmo espaço. São Paulo: Perspectiva. FLOCH, J. M. (1995) Sémiotique, marketing e communication. 2. ed., Paris: PUF. MATTOSO, G. (2004) Pegadas noturnas. Rio de Janeiro: Lamparina.

PIVA, R. (2005) Um estrangeiro na legião. São Paulo: Globo.

RIBEIRO, E. e BARBOSA, M. (2004) Cadernos negros - volume 27. São Paulo: Quilombhoje.

\section{Como citar este artigo:}

PIETROFORTE, Antonio Vicente. Você é lingüista ou pregador? Elaboração de uma tipologia estilística dos poetas brasileiros contemporâneos. Estudos Semióticos, Número 2, São Paulo, 2006. Disponível em <www.fflch.usp.br/dl/semiotica/es $>$. Acesso em "dia/mês/ano". 